\title{
STUDI PREFERENSI PENGELOLAAN PERPARKIRAN BERDASARKAN PELAYANAN, KETERSEDIAAN PRASARANA DAN RETRIBUSI DALAM MENUNJANG PAD KOTA MAKASSAR
}

\section{Preference Studies Based Parking Management Services, The Availability of Infrastructure and User Fees to Support Local Revenue the City of Makassar}

\author{
${ }^{1}$ Nur Khaerat Nur \\ Email:enkha93@gmail.com \\ ${ }^{1}$ Program Studi Teknik Sipil, Fakultas Teknik, Universitas Fajar, Makassar
}

\begin{abstract}
In the management of parking during this run visible indicators that can be used as a benchmark as the low contribution of parking service on revenue of Makassar and still less professional and optimal management of parking. This study aims to determine the level of optimization of the application of the parking management system by operators of parking based on public perception and analyze the level of service and high availability of parking facilities in the city of Makassar. This research was conducted by direct interview to the community and the spread of random questionnaires to determine public perceptions of parking management that are run during this and subsequent analysis of the level of service and availability of parking infrastructure by taking samples of the two locations in the city of Makassar. From the results of research in getting that parking geometric arrangement resulted in the design markings on the road Bougainville Makassar park consists of 26 markers and 20 markers of motor cars, while road markings Pengayoman consists of 146 cars and 54 motorcycles markers. Overall capacity of the car park on the street Bougainville 104 vehicles/h, the capacity of the car park on the street Pengayoman the west as much as 584 vehicles/hour. Capacity motorcycle parking on the street Bougainville as many as 80 vehicles/hour, capacity bike parking on the street Pengayoman the west as much as 216 vehicles / hour. For availability of parking facilities in addition to marking problems of parking, availability of infrastructure such as parking signs, SRP and parking attendants in Bougainville and western aegis not ideal should be added and equipped. Potential revenue (PAD), which can be generated at the study site from the calculation of the accumulation of cars and motorcycles parked vehicles every 15 minutes in the span of 13 hours every day for a week total daily average of Rp. 1,657,346. The respondent's perception of the overall entry in the medium category. For the highest score obtained at a frequency of parking of vehicles in the parking lot was not authorized by a score of 1054. While the lowest score in the delivery of tickets, with a score of 716. Overall it can be concluded that the availability of parking infrastructures is lacking and parking management systems are still considered less than optimal.
\end{abstract}

Keywords: Service Level, Peak Parking, levies, parking facilities and infrastructure

\section{PENDAHULUAN}

Kota Makassar sebagai kota yang sedang berkembang telah menunjukkan gejala-gejala tersebut. Laju pertumbuhan penduduk diikuti dengan pertumbuhan ekonomi yang menyebabkan kegiatan penduduk semakin meningkat. Sejalan dengan itu, maka peranan transportasi sangat diharapkan dalam menunjang segala bentuk kegiatan. Ketersediaan antara sarana dan prasarana transportasi yang memadai merupakan bentuk yang sangat menunjang dan cukup penting adalah penyediaan areal untuk parkir kendaraan.

Berkaitan dengan harapan di atas maka pembangunan kawasan perparkiran yang mencakup terciptanya kawasan perkotaan yang bersih, indah, aman dan rapi, diperlukan pembangunan titik parkir pada setiap kawasan bebas parkir, sehingga para pemilik kendaraan sebagai pengguna jasa perparkiran dapat 
memarkir kendaraannya dengan lebih aman, tenang dan tidak merasa khawatir akan terjadi resiko kehilangan kendaraan dalam meniti segala aktivitas kcsehariannya. Dengan demikian tatanan kehidupan yang bersih, indah aman dan rapi yang merupakan dambaan pemerintah dan masyarakat Makassar pada khususnya bahkan pemerintah dan masyarakat Sulawesi Selatan pada umumnya yang digaungkan dapat segera terwujud.

Menyadari arti pentingnya pengelolaan parkir yang baik dan efektif selain dapat menunjang program kota Makassar sebagai Kota Dunia, di samping yang tidak kalah pentingnya adalah menjadi salah satu sumber Pendapatan Asli Daerah (PAD) yang cukup rasional untuk dikembangkan. Perhatian pemerintah daerah Kota Makassar terhadap masalah perparkiran sebenamya di mulai sejak beberapa dekade yang lalu, namun harapan itu hampir dikatakan tidak pernah terwujud mengingat beberapa masalah pokok yang dihadapi seperti tidak tersedianya Sarana dan prasarana parkir yang memadai, kesadaran dan derajat ketertiban sebagian masyarakat yang masih relatif rendah dan pengelolaan perparkiran belum menjadi salah satu prioritas dalam menunjang aktivitas pembangunan. Salah satu indikator sementara yang dapat dijadikan sebagai tolak ukur yaitu rendahnya konstribusi jasa perparkiran terhadap pendapatan asli daerah Kota Makassar dan kurang profesional dan optimal dalam pengelolaan perparkiran.

Apabila penyediaan sarana dan prasarana perparkiran terutama pada kawasan bebas parkir tidak terkoordinir dan dikelola secara mantap dan terpadu. Walaupun diakui bahwa untuk mewujudkan operasi perparkiran yang baik dan efektif diakui banyaknya masalah yang dihadapi namun masalah-masalah tersebut dapat segera diatasi dengan adanya tekad, tanggung jawab dan kesadaran yang tinggi antara pemerintah daerah dan masyarakat.

Adapun tujuan penelitian ini adalah untuk mengetahui tingkat optimalisasi penerapan sistim pengelolaan perparkiran oleh pengelola perparkiran berdasarkan persepsi masyarakat dan menganalisis tingkat pelayanan dan tingkat ketersediaan parasarana perparkiran di Kota Makassar.

\section{METODE PENELITIAN}

\section{Pengumpulan Data}

Pengumpulan data dilakukan dengan cara

a. Wawancara berstruktur (Kuesioner), yaitu dengan cara melakukan wawancara langsung kegiatan responden dengan menggunakan daftar pertanyaan.

b. Wawancara bebas, yaitu data-data yang ingin diketahui secara mendalam melalui wawancara yang tidak berstruktur, utamanya untuk menggali informasi yang bersifat umum dari pengguna kendaraan maupun pengelola parkir Kota Makassar serta sumber lainnya.

c. Pengamatan lapangan (observasi), yaitu melalui pengamatan langsung terhadap kondisi perparkiran untuk memperoleh gambaran umum tentang kondisi perparkiran pada obyek penelitian, meliputi

- Kinerja pelayanan prasarana parkir oleh pengelola Parkir Kota Makassar

- Bagaimana kondisi tingkat ketersediaan prasarananya seperti: jalan, ramburambu,

- Sirkulasi kendaraan, median jalan dan marka parkir.

\section{Teknik Analisa Data}

Adapun teknik analisa data adalah:

a. Menghitung Tingkat Ketersediaan Prasarana Parkir

\section{Durasi Parkir}

Lama waktu parkir atau durasi adalah lama waktu yang dihabiskan oleh pemarkir pada ruang parkir. Lamanya parkir di-nyatakan dalam jam. Rumus yang digunakan untuk menghitung rata-rata lamanya parkir adalah (Oppenlander, 1976):

Keterangan,

$$
D=\frac{N_{x} \cdot X \cdot I}{N_{t}}
$$

$\mathrm{D}$ = Rata-rata lama parkir atau durasi; Jam/kendaraan

$\mathrm{N}_{\mathrm{x}}=$ Jumlah Kendaraan yang parkir selama interval waktu survey

$\mathrm{X}=$ Jumlah dari interval

$\mathrm{I}=$ Interval waktu

$\mathrm{N}_{\mathrm{t}}=$ Jumlah total kendaraan selama waktu survey 


\section{Kapasitas Parkir}

Untuk mengetahui jumlah kapasitas parkir digunakan rumus:

$$
\mathrm{K}=\frac{\mathrm{S}}{\mathrm{D}}
$$

Di mana:

$\mathrm{K}=$ Kapasitas

$\mathrm{S}=$ Jumlah Marka

$\mathrm{D}=$ Durasi waktu

\section{Penentuan Volume Jam Puncak Parkir}

Volume puncak parkir adalah jumlah kendaraan yang diparkir pada suatu tempat selama selang waktu satu hari. Penentuan jumlah parkir diperlukan untuk mengetahui intensitas penggunaan ruang parker oleh kendaraan. Analisa tentang jumlah parkir menggambarkan karakteristik penggunaan ruang parkir dalam jangka waktu yang cukup panjang. Kemudian juga untuk mengetahui bagaimana karakteristik penggunaan ruang jalan, bagaimana fluktuasi parkir dan kapan jam-jam puncak serta berapa jumlah parkir pada jam puncak tersebut. Penentuan volume jam kerja parker sangat berkaitan dengan perencanaan penyediaan parker pada suatu kawasan studi, hal ini perlu diperhatikan adalah berapa besar kebutuhan parkir pada daerah tersebut dan berapa besar kebutuhan sudut parkirnya sehingga dapat dicapai suatu optimasi penggunaan ruang jalan yang menyebabkan gangguan terhadap lalulintas dapat ditekan atau relative berkurang.

Penelitian dilakukan dengan pengamatan langsung di lapangan selama satu minggu pada daerah studi.

$$
\text { Volume }=\mathrm{Nin}+\mathrm{X}(\text { kendaraan })
$$

Keterangan:

$$
\begin{aligned}
\text { Nin }= & \text { Jumlah kendaraan yang masuk } \\
& \text { (kendaraan). } \\
X= & \begin{array}{l}
\text { Kendaraan yang sudah ada sebelum } \\
\text { waktu survei }
\end{array}
\end{aligned}
$$

b. Perhitungan Jumlah Retribusi Parkir

Untuk mengetahui jumlah retribusi parkir yang didapatkan pada lokasi penelitian dalam per hari selama seminggu yakni dengan menghitung akumulasi parkir kendaraan mobil dan motor dalam interval 15 menit selama13 jam yakni dari jam 8.00sampai jam 21.00 lalu dikalikan dengan biaya retribusi parkir per kendaraan, berdasarkan penetapan harga parkir kendaraan yang telah ditetapkan oleh Pemkot Makassar yang dikelola oleh Perusda Parkir Kota Makassar.

c. Perancangan sistem ruang parkir on street

Dalam merancang sistem ruang parkir on street di lokasi penelitian yakni dengan menampilkan desain gambar berdasarkan jumlah marka parkir, lebar jalan, panjang jalan, dan rambu parkir

d. Teknik Analisis Preferensi Publik Dalam Pengelolaan Prasarana Parkir

Dalam penelitian ini digunakan teknik analisis data dengan metode statistik deskriptif kualitatif, deskriptif kualitatif dan metode analisis statistic regresi sebagai berikut:

\section{Metode Statistik Deskriptif}

Untuk mengetahui persentase dari frekuensi terhadap jumlah sample digunakan rumus:

$$
P=\frac{f}{n} \times 100 \%
$$

(Sujana, 1996: 50)

Di mana:

$\mathrm{P}=$ Persentase Responden

$\mathrm{F}=$ Frekuensi kategori pilihan

$\mathrm{n}=$ Jumlah sampel

\section{Metode Deskriptif Kualitatif}

Metode ini digunakan untuk menjelaskan tentang tingkat ketersediaan prasarana fisik dan tingkat pelayanan menurut persepsi masyarakat di kawasan perumahan Bukit Baruga kota Makassar. Dalam analisa data, teknik atau metode yang digunakan adalah tabulasi dan persentase dengan metode pengukuran skala Likert (Sugiyono, 2002:73). Data yang terkumpul selanjutnya akan dilakukan penentuan kategori dan rating skor. 


\section{Definisi Operasional}

Untuk memberikan gambaran secara jelas mengenai masalah yang diteliti tentang variabel, indikator dan cara mengukurnya, maka perlu diberikan beberapa definisi operasional.

Dalam penentuan kriteria dam kategori penilaian, yaitu melalui pertanyaan dalam kuesioner yang dibagikan kepada masing masing responden di daerah penelitian. Dari setiap pertanyaan terdapat 4 (empat) alternatif pilihan jawaban dengan penilaian skala Likert (Sugiyono, 2002:73) sebagai berikut:

\section{Untuk Jawaban:}

5 bila pilihan: sangat tahu, sangat baik, sangat sering, sangat puas dan sangat tersedia

4 bila pilihan: baik, tahu, sering, puas dan tersedia

3 bila pilihan: cukup tahu, cukup baik, kadang-kadang, biasa saja, cukup tersedia

2 bila pilihan: kurang tahu, kurang baik, kurang tersedia, kurang puas dan kurang tersedia/jarang

1 bila pilihan: tidak tahu, tidak baik, tidak pernah, tidak tersedia, tidak puas, tidak tersedia

$$
\text { Skor responden }=\sum_{i=1}^{n} \mathrm{f}(\mathrm{i}) \mathrm{x} \text { bobot }
$$

Skor tertinggi $=336 \times 5=1680$

Skor terendah $=336 \times 1=336$

Rentang tiap kriteria (Husain Umar 2003: 164)

$$
\mathrm{RS}=\frac{\mathrm{n}(\mathrm{m}-1)}{\mathrm{m}}
$$

$\mathrm{n}=$ jumlah sampel

$\mathrm{m}=$ jumlah alternative jawaban tiap item

$\mathrm{RS}=\frac{336(5-1)}{5}$

$\mathrm{RS}=268,9=269$ dibulatkan

Penentuan rentang penilaian adalah:

$$
\begin{array}{ll}
\text { Sangat Tinggi } & =1416-1680 \\
\text { Tinggi } & =11 / 46-1415 \\
\text { Sedang } & =876-1145 \\
\text { Rendah } & =606-875 \\
\text { Sangat Rendah } & =336-605
\end{array}
$$

\section{ANALISA DAN PEMBAHASAN}

\section{Analisis Ketersediaan Prasarana Parkir}

Dari hasil observasi ketersediaan prasarana parkir di Jalan Bougainville dan Jalan Pengayoman bagian barat yang telah dilakukan pengambilan data pada Juni 2015, dimulai pada tanggal 12 Juni hingga 18 Juni 2015, Observasi dilakukan dengan pengamatan langsung dan melakukan olah data sebagai berikut:

Tabel 2. Hasil Observasi dan Olah Data prasarana parkir On Street Parking

\begin{tabular}{c|l|c|c|c|c}
\hline \multirow{2}{*}{ No. } & \multirow{2}{*}{$\begin{array}{c}\text { Kebutuhan } \\
\text { Prasarana }\end{array}$} & $\begin{array}{c}\text { Bougainville } \\
\text { Utara ke Selatan }\end{array}$ & $\begin{array}{c}\text { Ketersediaan Prasarana Parkir } \\
\text { Belatan ke Utara }\end{array}$ & $\begin{array}{c}\text { Pengayoman } \\
\text { Barat Ke Timur }\end{array}$ & $\begin{array}{c}\text { Pengayoman } \\
\text { Timur ke Barat }\end{array}$ \\
\cline { 3 - 6 } $\mathbf{1}$ & Lahan Parkir & $214,0 \mathrm{~m}$ & $214,0 \mathrm{~m}$ & $562,50 \mathrm{~m}$ & $562,50 \mathrm{~m}$ \\
\hline $\mathbf{2}$ & Marka Parkir & - & 26 dan 20 & 74 dan 54 & 72 \\
\hline $\mathbf{3}$ & Rambu Parkir & 4 & 4 & 7 & 7 \\
\hline $\mathbf{4}$ & SRP & - & $2,5 \times 5,0$ & $0,75 \times 2,0$ & $2,5 \times 5,0$ \\
\hline $\mathbf{5}$ & Juru Parkir & 6 orang & 5 orang & 18 orang & 16 orang \\
\hline
\end{tabular}

Sumber: Hasil Olah Data 2015

Berdasarkan hasil observasi di lapangan jalan Bougainville dan Jalan Pengayoman adalah dua jalan yang sangat padat aktivitas dalam kawasan kota Makassar. Dua jalan ini merupakan area perdagangan, perkantoran dan pusat kegiatan publik yang mana membutuhkan perhatian akan penataan dan ketersediaan prasarana parkir. Problematika yang sering muncul di tengah-tengah masyarakat mengenai fasilitas parkir antara lain, lahan parkir, tarif parkir, kenyamanan serta pelayanan parker pengguna parkir menginginkan terdapat ruang parkir yang dekat dengan tempat tujuan yakni tempat tempat yang ramai di mana kebutuhan parkir sangat tinggi, keadaan seperti ini acapkali menimbulkan persoalan yang serius. Belum 
lagi keinginan pemilik kendaraan mendapatkan jaminan keamanan atas kendaraan mereka yang ditinggalkan menjadi satu akumulasi persoalan pelayanan yang bersentuhan langsung akan ketersediaan prasarana parkir yang nyata dan optimal.
Karenanya untuk mengantisipasi dan mengatasi masalah itu pengelola parkir, harusnya pemerintah atau pihak swasta menjadikan permasalahan ini sebagai prioritas pokok karena telah bersentuhan langsung dengan kebutuhan dan pelayanan publik.

Tabel 3. Distribusi Volume Parkir di hari dan jam puncak

\begin{tabular}{|c|c|c|c|c|c|c|c|}
\hline \multirow[b]{2}{*}{$\begin{array}{c}\text { Hari } \\
\text { Dengan } \\
\text { Volume } \\
\text { Parkir } \\
\text { Puncak }\end{array}$} & \multirow[b]{2}{*}{$\begin{array}{c}\text { Jenis } \\
\text { Kendaraan }\end{array}$} & \multicolumn{3}{|c|}{ Bougainville } & \multicolumn{3}{|c|}{ Pengayoman Barat } \\
\hline & & $\begin{array}{c}\text { Jam } \\
\text { Puncak } \\
\text { Parkir }\end{array}$ & $\begin{array}{c}\text { Lama } \\
\text { Parkir } \\
\text { Puncak } \\
\text { (jam) }\end{array}$ & $\begin{array}{c}\text { Volume } \\
\text { Puncak } \\
\text { Parkir }\end{array}$ & $\begin{array}{c}\text { Jam } \\
\text { Puncak } \\
\text { Parkir }\end{array}$ & $\begin{array}{c}\text { Lama } \\
\text { Parkir } \\
\text { Puncak } \\
\text { (jam) }\end{array}$ & $\begin{array}{c}\text { Volume } \\
\text { Puncak } \\
\text { Parkir }\end{array}$ \\
\hline \multirow{2}{*}{ Senin } & Mobil & $15.15-16.30$ & $\begin{array}{l}0.25- \\
1.25\end{array}$ & 173 & $\begin{array}{c}14.45- \\
15.45\end{array}$ & $0.25-1$ & 566 \\
\hline & Motor & $14.30-15.45$ & $\begin{array}{c}0.15- \\
1,25\end{array}$ & 451 & $\begin{array}{c}17.00- \\
18.00\end{array}$ & $0.25-1$ & 372 \\
\hline \multirow[b]{2}{*}{ Selasa } & Mobil & $13.30-14.45$ & $\begin{array}{l}0.25- \\
1.25\end{array}$ & 159 & $\begin{array}{l}14.30- \\
15.45\end{array}$ & $0.25-1.25$ & 582 \\
\hline & Motor & $15.00-16.15$ & $\begin{array}{l}0.25- \\
1.25\end{array}$ & 366 & $\begin{array}{c}18.45- \\
20.00\end{array}$ & $0.25-1.25$ & 318 \\
\hline \multirow[t]{2}{*}{ Rabu } & Mobil & $14.00-15.00$ & $0.25-1$ & 158 & $\begin{array}{c}14.30- \\
15.30\end{array}$ & $0.25-1$ & 525 \\
\hline & Motor & $16.15-17.15$ & $\begin{array}{c}0.15- \\
1.25\end{array}$ & 264 & $\begin{array}{c}17.30- \\
18.30\end{array}$ & $0.25-1$ & 311 \\
\hline \multirow{2}{*}{ Kamis } & Mobil & $14.15-15.15$ & $0.25-1$ & 139 & $\begin{array}{c}13.30- \\
14.30 \\
\end{array}$ & $0.25-1$ & 503 \\
\hline & Motor & $14.15-15.30$ & $\begin{array}{c}0.25- \\
1.25\end{array}$ & 174 & $\begin{array}{c}11.45- \\
12.45\end{array}$ & $0.25-1$ & 121 \\
\hline \multirow{2}{*}{ Jumat } & Mobil & $15.30-16.30$ & $0.25-1$ & 118 & $\begin{array}{c}15.00- \\
16.15\end{array}$ & $0.25-1.25$ & 385 \\
\hline & Motor & $\begin{array}{c}15.45-17.00 \\
\& 16.45- \\
17.45\end{array}$ & $\begin{array}{l}0.25- \\
1.25\end{array}$ & 311 & $\begin{array}{c}14.45- \\
15.45\end{array}$ & $0.25-1$ & 192 \\
\hline \multirow{2}{*}{ Sabtu } & Mobil & $14.30-15.30$ & $0.25-1$ & 164 & $\begin{array}{c}14.30- \\
15.45 \\
\end{array}$ & $0.25-1.25$ & 593 \\
\hline & Motor & $14.00-15.00$ & $0.25-1$ & 656 & $\begin{array}{c}20.00- \\
21.00\end{array}$ & $0.25-1$ & 295 \\
\hline \multirow{2}{*}{ Minggu } & Mobil & $16.15-17.15$ & $0.25-1$ & 176 & $\begin{array}{c}14.30- \\
15.30\end{array}$ & $0.25-1$ & 556 \\
\hline & Motor & $16.15-17.15$ & $0.25-1$ & 567 & $\begin{array}{c}17.00- \\
18.15\end{array}$ & $0.25-1.25$ & 273 \\
\hline
\end{tabular}

Sumber: Hasil olah data 2015

Hasil pengukuran dalam parkir dapat diketahui kondisi perparkiran yang terjadi pada lokasi studi seperti mencakup volume parkir, akumulasi parkir, lama waktu parkir, angka pergantian parkir, kapasitas parkir. Untuk lebih jelasnya dapat dilihat pada Tabel 4 di bawah ini:

Tabel 4. Pengukuran/Besaran dalam Parkir

\begin{tabular}{|c|c|c|c|c|c|c|c|c|c|c|c|c|c|c|c|}
\hline \multirow{2}{*}{$\begin{array}{c}\text { Hari } \\
\text { Dengan } \\
\text { Volume } \\
\text { Parkir }\end{array}$} & \multirow[b]{2}{*}{$\begin{array}{c}\text { Jenis } \\
\text { Kendaraan }\end{array}$} & \multicolumn{7}{|c|}{ Bougainville } & \multicolumn{7}{|c|}{ Pengayoman Barat } \\
\hline & & Nt & $\mathbf{X}$ & $\mathbf{N x}$ & I & D & $\mathbf{S}$ & $\mathbf{K}$ & $\mathbf{N t}$ & $\mathbf{X}$ & $\mathbf{N x}$ & I & D & $\mathbf{S}$ & $\mathbf{K}$ \\
\hline \multirow{2}{*}{ Senin } & Mobil & 1425 & 52 & 27 & 0.25 & 0.25 & 26 & 104 & 4852 & 52 & 93 & 0.25 & 0.25 & 146 & 584 \\
\hline & Motor & 3399 & 52 & 65 & 0.25 & 0.25 & 20 & 80 & 2393 & 52 & 46 & 0.25 & 0.25 & 54 & 216 \\
\hline
\end{tabular}




\begin{tabular}{|c|c|c|c|c|c|c|c|c|c|c|c|c|c|c|c|}
\hline \multirow{2}{*}{$\begin{array}{c}\text { Hari } \\
\text { Dengan } \\
\text { Volume } \\
\text { Parkir }\end{array}$} & \multirow{2}{*}{$\begin{array}{c}\text { Jenis } \\
\text { Kendaraan }\end{array}$} & \multicolumn{7}{|c|}{ Bougainville } & \multicolumn{7}{|c|}{ Pengayoman Barat } \\
\hline & & Nt & $\mathbf{X}$ & $\mathbf{N x}$ & I & D & $\mathbf{S}$ & $\mathbf{K}$ & $\mathrm{Nt}$ & $\mathbf{X}$ & $\mathbf{N x}$ & I & D & $\mathbf{S}$ & $\mathbf{K}$ \\
\hline \multirow{2}{*}{ Selasa } & obil & 1444 & 52 & 28 & .25 & 25 & 26 & 104 & 282 & 52 & 102 & 0.25 & 0.25 & 146 & 584 \\
\hline & Motor & 2854 & 52 & 55 & 0.25 & 0.25 & 20 & 80 & 2665 & 52 & 51 & 0.25 & 0.25 & 54 & 216 \\
\hline \multirow{2}{*}{ Rabu } & & 61 & 52 & 26 & 0.25 & 025 & 26 & 104 & 4261 & 52 & 82 & 0.25 & 0.25 & 146 & 584 \\
\hline & & & 52 & 46 & 0.25 & & 20 & 80 & 2354 & 52 & 45 & .25 & 0.25 & 54 & 216 \\
\hline \multirow{2}{*}{ Kamis } & & & & 21 & & & 26 & 10 & 348 & 52 & & & & 146 & 584 \\
\hline & & 145 & 52 & 28 & 0.25 & 0.2 & 20 & 8 & 1235 & 52 & 24 & 0.25 & 0.25 & 54 & 216 \\
\hline \multirow{2}{*}{ Jumat } & $\mathrm{M}$ & 1019 & 52 & 20 & 0.25 & 0.25 & 26 & 104 & 3496 & 52 & 67 & 0.25 & 0.25 & 146 & 584 \\
\hline & & 2436 & 52 & 47 & 0.25 & 0.25 & 20 & 80 & 1408 & 52 & 27 & 0.25 & .25 & 54 & 216 \\
\hline \multirow{2}{*}{ Sabtu } & & 1624 & 52 & 31 & 0.25 & 0.25 & 26 & 104 & 5132 & 52 & 99 & 0.25 & 0.25 & 146 & 584 \\
\hline & & 5193 & 52 & 100 & 0.25 & 0.25 & 20 & 80 & 2048 & 52 & 39 & 0.25 & 0.25 & 54 & 216 \\
\hline \multirow{2}{*}{ Minggu } & & 1458 & 52 & 28 & 0.25 & 0.2 & 26 & 104 & 4071 & 52 & 78 & 0.25 & 0.25 & 146 & 584 \\
\hline & Motor & 3534 & 52 & 68 & 0.25 & 0.25 & 20 & 80 & 2218 & 52 & 43 & 0.25 & 0.25 & 54 & 216 \\
\hline
\end{tabular}

Sumber: Hasil olah data 2015

Dengan demikian secara akumulatif dari keseluruhan data dan perhitungan pengukuran dan besaran parkir pada table di atas, dapat diketahui bahwa kapasitas parkir pada lokasi penelitian adalah:

a. Kapasitas Parkir Mobil Bougainville: 104 kendaraan/jam

b. Kapasitas Parkir Mobil Pengayoman bagian barat: 584 kendaraan/jam

c. Kapasitas Parkir Motor Bougainville: 80 kendaraan/jam

d. Kapasitas Parkir Motor Pengayoman bagian barat: 216 kendaraan/jam

\section{Sistem Penataan Ruang Parkir}

Dalam menciptakan ruang parkir yang ideal pada ruas jalan Bougainvillea dan jalan Pengayoman, maka diuraikan sistem penataan ruang parkir pada tabel di bawah ini sebagai berikut:

Tabel 5. Sistem penataan ruang parkir

\begin{tabular}{l|l|c|c}
\hline \multirow{2}{*}{ No. } & \multirow{2}{*}{$\begin{array}{c}\text { Jenis } \\
\text { Prasarana }\end{array}$} & \multicolumn{2}{|c}{ Nama Jalan } \\
\cline { 3 - 4 } & & Bougainville & $\begin{array}{c}\text { Pengayoman } \\
\text { Barat }\end{array}$ \\
\hline 1. & Marka Mobil & 26 & 146 \\
\hline 2. & Marka Motor & 20 & 54 \\
\hline 3. & $\begin{array}{l}\text { Derajat } \\
\text { Marka }\end{array}$ & $0^{\circ}$ & $0^{\circ}$ \\
\hline 4. & Lebar Jalan & $8,2 \mathrm{~m}$ & $10 \mathrm{~m}$ \\
\hline 5. & Panjang Jalan & $214 \mathrm{~m}$ & $562,5 \mathrm{~m}$ \\
\hline 6. & Rambu Parkir & 8 & 14 \\
\hline
\end{tabular}

Sumber: Hasil olah data penelitian 2015

Geometrik parkir menghasilkan desain penataan marka parkir pada jalan Bougainville Makassar terdiri dari 26 marka mobil dan 20 marka motor, sedangkan Jalan Pengayoman terdiri dari 146 marka mobil dan 54 marka motor.

Marka parkir di jalan Bougainville dan Pengayoman Makassar menggunakan pola parkir lurus atau 0 derajat atau disebut pula pola paralel. Hal ini dikarenakan Jalan Bougainville dalam pengukuran di lapangan memiliki lebar total jalan 8,2 meter dan panjang jalan 214 meter, yang berarti memenuhi persyaratan aturan Dirjen Perhubungan Darat bahwa syarat jalan lokal sekunder dalam mendesain marka parkir onstreet minimal 7,8 meter dengan sudut parkir 0 derajat atau paralel. Sedangkan Jalan Pengayoman selaku jalan lokal primer memiliki lebar 10 meter dan panjang jalan 562,5 meter memenuhi persyaratan aturan yang dikeluarkan Dirjen perhubungan darat bahwa syarat minimal total lebar jalan 9,8 meter untuk parkir kemiringan 0 derajat atau paralel. Untuk jumlah rambu Parkir di jalan Bougainville sebanyak 8 buah rambu dan jalan Pengayoman Barat sebanyak 14 buah rambu. Adapun rancangan gambar sistem penataan parkir pada lokasi penelitian dapat dilihat pada halaman lampiran.

\section{Analisis perhitungan Pendapatan Retribusi Parkir}

Berdasarkan hasil perhitungan akumulasi parkir kendaraan mobil dan motor setiap 15 menit dalam rentang waktu 13 jam dari setiap hari selama seminggu di masing-masing lokasi penelitian maka didapatkan potensi 
pendapatan retribusi parkir kendaraan dan motor yakni total rata-rata per hari sebesar Rp
1.657.346. Untuk lebih jelasnya dapat dilihat pada Tabel di bawah ini sebagai berikut:

Tabel 6. Analisis perhitungan retribusi parkir

\begin{tabular}{|c|c|c|c|c|c|c|c|c|}
\hline \multirow{3}{*}{ No. } & \multirow{3}{*}{$\begin{array}{c}\text { Nama } \\
\text { Hari }\end{array}$} & \multicolumn{4}{|c|}{ Kapasitas Parkir } & \multirow{2}{*}{\multicolumn{2}{|c|}{$\begin{array}{c}\text { Jumlah Pendapatan } \\
(\text { mobil }=\text { Rp 2000,- , motor }=\text { Rp } \\
1.000,- \text { ) }\end{array}$}} & \multirow{3}{*}{$\begin{array}{c}\text { Total } \\
\text { Jumlah } \\
\text { Pendapatan }\end{array}$} \\
\hline & & \multicolumn{2}{|c|}{$\begin{array}{c}\text { Jalan } \\
\text { Bougainville }\end{array}$} & \multicolumn{2}{|c|}{$\begin{array}{c}\text { Jalan Pengayoman } \\
\text { Barat }\end{array}$} & & & \\
\hline & & Mobil & Motor & Mobil & Motor & Mobil & Motor & \\
\hline 1. & Senin & 109 & 259 & 371 & 182 & 958,731 & 881,538 & $1,840,269$ \\
\hline 2. & Selasa & 110 & 217 & 403 & 203 & $1,026,692$ & 840,846 & $1,867,538$ \\
\hline 3. & Rabu & 104 & 217 & 325 & 179 & 858,115 & 791,731 & $1,649,846$ \\
\hline 4. & Kamis & 83 & 182 & 267 & 93 & 699,692 & 548,269 & $1,247,962$ \\
\hline 5. & Jumat & 78 & 112 & 267 & 107 & 689,231 & 436,462 & $1,125,692$ \\
\hline 6. & Sabtu & 112 & 271 & 392 & 156 & $1,007,538$ & 853,154 & $1,860,692$ \\
\hline 7. & Minggu & 124 & 398 & 313 & 171 & 872,769 & $1,136,654$ & $2,009,423$ \\
\hline \multicolumn{8}{|c|}{ Jumlah rata - rata } & $1,657,346$ \\
\hline
\end{tabular}

Sumber: Hasil olah data penelitian 2015

\section{Analisis Preferensi Publik Ketersediaan Prasarana Parkir dan Pengelolaan Perparkiran}

Berdasarkan distribusi responden terhadap tingkat ketersediaan prasarana parkir dan pengelolaan perparkiran di kota Makassar, dapat diketahui bahwa secara menyeluruh, rata-rata responden menilai ketersediaan prasarana parkir dan pengelolaan perparkiran di kota Makassar, berada pada kategori Sedang, Dengan demikian secara keseluruhan preferensi publik terhadap ketersediaan prasarana parkir dan pengelolaan perparkiran di kota Makassar masih dalam kondisi kurang memadai dan belum optimal serta belum sesuai dengan standar peraturan yang ditetapkan, dalam hal ini tentunya diharapkan perhatian pemerintah kota Makassar terkhusus kepada pengelola perparkiran yakni Perusda Perparkiran Kota Makassar untuk dapat lebih melengkapi ketersediaan prasarana parkir dan memperbaiki sistem pengelolaan perparkiran demi terciptanya pengelolaan perparkiran professional, aman dan tertib. Untuk lebih detailnya dapat kita lihat pada Tabel 7 di bawah ini:

Tabel 7. Distribusi responden berdasarkan keseluruhan kondisi tingkat ketersediaan prasarana parkir dan pengelolaan perparkiran

\begin{tabular}{|c|c|c|c|c|c|c|c|c|}
\hline \multirow{2}{*}{ No. } & \multirow{2}{*}{ Uraian Responden } & \multicolumn{5}{|c|}{ Jawaban Responden } & \multirow{2}{*}{$\begin{array}{l}\text { Total } \\
\text { Skor }\end{array}$} & \multirow{2}{*}{ Kategori } \\
\hline & & 5 & 4 & 3 & 2 & 1 & & \\
\hline 1. & Peraturan parkir & 95 & 340 & 378 & 176 & 18 & 1007 & Sedang \\
\hline 2. & Sistem Pelayanan parkir & 10 & 100 & 315 & 332 & 38 & 795 & Sedang \\
\hline 3. & Parkir resmi dan tidak resmi & 145 & 388 & 231 & 204 & 31 & 999 & Sedang \\
\hline 4. & $\begin{array}{l}\text { Frekuensi Parkir di tempat parkir tidak } \\
\text { resmi }\end{array}$ & 95 & 316 & 543 & 86 & 14 & 1054 & Sedang \\
\hline 5. & Pelayanan parkir tidak resmi & 0 & 76 & 315 & 304 & 60 & 755 & Sedang \\
\hline 6. & Karcis parkir & 30 & 76 & 294 & 206 & 110 & 716 & Sedang \\
\hline 7. & Tingkat Parkir & 30 & 136 & 396 & 248 & 40 & 850 & Sedang \\
\hline 8. & Ketersediaan prasarana parkir & 0 & 96 & 297 & 404 & 11 & 808 & Sedang \\
\hline 9. & Juru Parkir & 15 & 152 & 390 & 286 & 22 & 865 & Sedang \\
\hline
\end{tabular}

Sumber: Hasil olah data 2015 


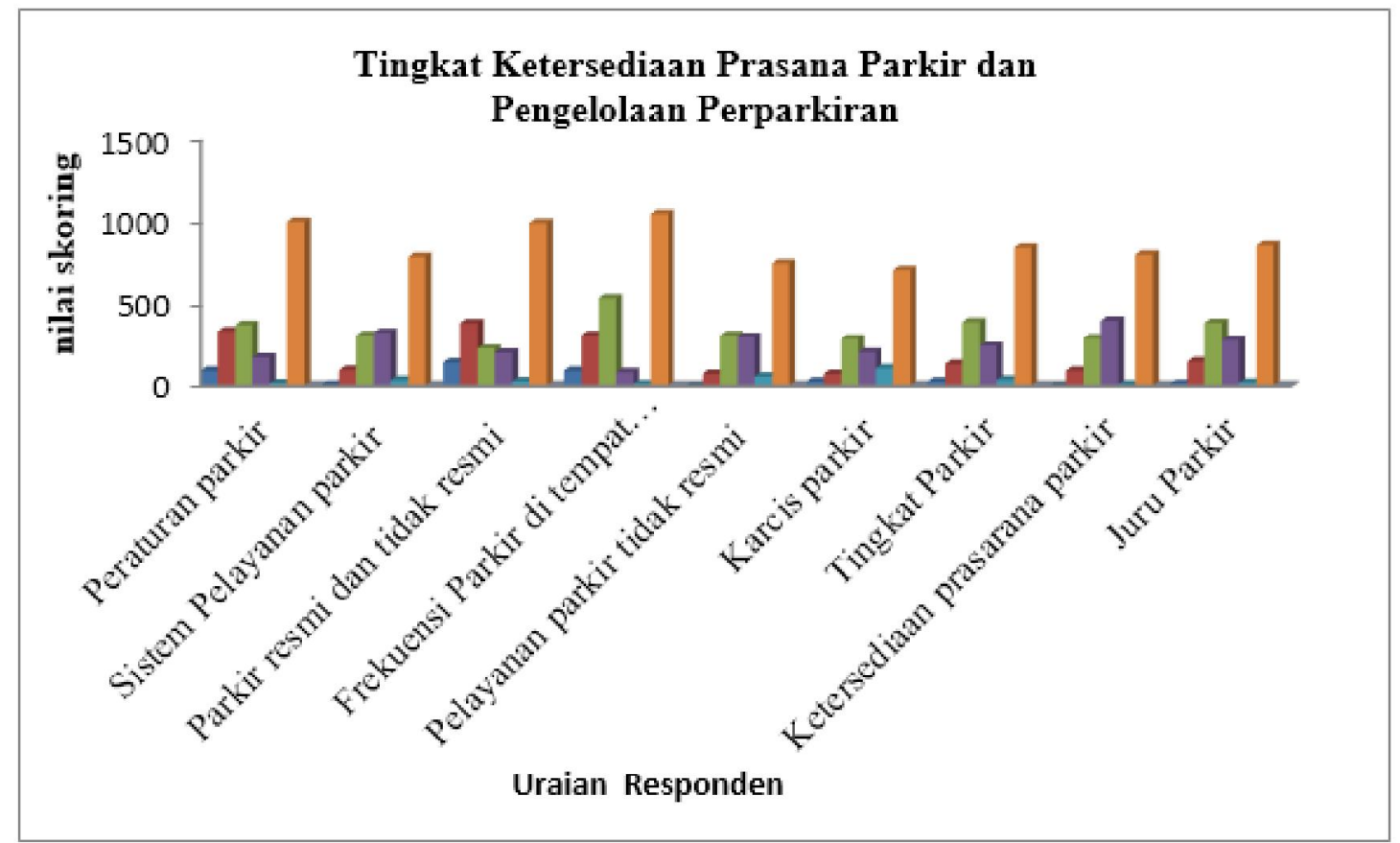

Gambar 1. Grafik distribusi responden berdasarkan keseluruhan kondisi tingkat ketersediaan prasarana parkir dan pengelolaan perparkiran kota Makassar.

\section{KESIMPULAN DAN SARAN}

\section{Kesimpulan}

1. Geometrik parkir menghasilkan desain penataan marka parkir pada jalan Bougainville Makassar terdiri dari 26 marka mobil dan 20 marka motor, sedangkan Jalan Pengayoman terdiri dari 146 marka mobil dan 54 marka motor

a. Jalan Bougainville dalam pengukuran kami memiliki lebar total jalan 8,2 Meter yang berarti memenuhi persyaratan aturan Dirjen Perhubungan Darat bahwa syarat jalan lokal sekunder dalam mendesain marka parkir onstreet minimal 7,8 meter dengan sudut parkir 0 derajat atau paralel. Sedangkan Jalan Pengayoman selaku jalan lokal primer memiliki lebar 10 meter memenuhi persyaratan aturan yang dikeluarkan Dirjen perhubungan darat bahwa syarat minimal total lebar jalan 9,8 meter untuk parkir kemiringan 0 derajat atau paralel.

b. Selain masalah marka parkir, ketersediaan prasarana parkir lain seperti rambu parkir, SRP dan juru parkir di Bougainville dan Pengayoman barat belum ideal mestinya ditambahkan dan dilengkapi.

2. Secara akumulatif dari keseluruhan data dan perhitungan kapasitas parkir di Jalan Bougainville dan Pengayoman didapatkan secara keseluruhan kapasitas parkir dengan menggunakan rumus Kapasitas dan Durasi Parkir sebagai berikut:

a. Kapasitas Parkir Mobil Bougainville: 104 kendaraan/jam

b. Kapasitas Parkir Mobil Pengayoman bagian barat: 584 kendaraan/jam

c. Kapasitas Parkir Motor Bougainville: 80 kendaraan/jam

d. Kapasitas Parkir Motor Pengayoman bagian barat: 216 kendaraan/jam

3. Potensi pendapatan yang dapat dihasilkan pada lokasi penelitian berdasarkan hasil perhitungan akumulasi parkir kendaraan mobil dan motor setiap 15 menit dalam rentang waktu 13 jam dari setiap hari selama seminggu yakni total rata-rata per hari sebesar Rp. 1.657.346,-

4. Dari korespondensi 336 responden atas 10 pertanyaan secara rata-rata keseluruhan responden menjawab, pada skor kualitatif Likert ialah masuk pada kategori sedang. Namun rata-rata kategori sedang berada pada skor yang berbeda beda mengakibatkan kategori sedang 
berkecenderungan dekat pada kategori Tinggi dan Rendah. Skor ini juga memberikan gambaran kualitatif atas tingkatan jawaban responden dengan skor terendah hingga tertinggi di mana skor tertinggi pada pertanyaan untuk responden bagaimana frekuensi memarkir kendaraan pada tempat parkir tidak resmi, responden menjawab dengan skor 1054. Sedangkan skor terendah pada pertanyaan setiap parkir di tempat tidak resmi apakah diberi karcis, responden menjawab dengan skor 716.

\section{Saran}

1. Perusahaan Daerah Parkir Kota Makassar sebagai penanggung jawab Pelaksanaan perparkiran di bahu jalan On Street Parking agar lebih memperhatikan ketersediaan prasarana di kedua jalan itu yang pada akhirnya tidak menyebabkan kesemrawutan dan kemacetan.

2. Over Kapasitas membuat daerah manfaat jalan untuk arus lalulintas di jam-jam puncak menjadi menyempit dan mengakibatkan kemacetan diperlukan petugas untuk mengatur ketertiban dan kedisiplinan

3. Over Kapasitas dapat ditekan pada jam-jam puncak apabila perkantoran dan pertokoan yang menjadi sentra aktivitas, seperti Mall, menyiapkan lahan parkir yang memadai off street parking. Agar pengguna parkir tidak meluber ke jalan-jalan dan mengganggu kelancaran lalu lintas

4. Over Kapasitas bisa disebabkan karena mahalnya biaya parkir pada off street parking hingga mengakibatkan parkir di bahu jalan sebagai alternatif

5. Over Kapasitas parkir On Street pada jamjam puncak, pengendaliannya dapat dilakukan dengan pembatasan waktu parkir atau menaikkan harga tiket karcis pada daerah-daerah over.

6. Terkait hasil respondensi, pemerintah Kota Makassar sebaiknya melakukan sosialisasi pemahaman tentang regulasi perparkiran, membuat kebijakan parkir yang lebih simpel, murah dan nyaman.

7. Untuk meningkatkan Pendapatan asli daerah (PAD) Kota Makassar, maka sebaiknya pengelolaan perparkiran harus dijalankan secara professional

\section{DAFTAR PUSTAKA}

Andung Y, Kami Hari B., Eko Y,2006, Pengaruh Manuver Kendaraan Parkir Badan Jalan Terhadap Karakteristik Lalu Lintas Di Jalan Diponegoro Yogyakarta, Program Magister Universitas Diponegoro.

Anonimus. 2013. Kotamadya Ujung Pandang Dalam Angka, 2013, Kantor Statistik Tingkat Sulawesi Selatan.

Arif Ramadhan. Seri penuntun Praktis SQL Server 2000 dan Visual Basic 6.0, Jakarta: Elex Media Komputindo.

Hamid. 2010. Pengembangan Sistem Parkir Terkomputerisasi dengan Otomatisasi Pembiayaan dan Penggunaan RFID Sebagai Pengenal Unik Pengguna. Seminar Nasional Aplikasi Teknologi Informasi. ISSN: 1907-5022

Parkir,http://elisal.ugm.ac.id/files/dinawk/Kp gAkEhQ/Seno-Ratna- Jasa $\% 20$ Parkiran.pdf, 04 November 2010

Mahrus Sabang, Rhiza S. Sadjad, Merna Baharuddin,2012. Sistem Parkir Cerdas, Jurusan Teknik Elektro Universitas Hasanuddin.

Peraturan Pemerintah No. 43, Tahun 1993, Analisis Kebutuhan Parkir, http://fportfolio.petra.ac.id/userfiles/0106 5/Analis \%20 Kebutuhan \% 20 Parkir.ppt, 04 November 2010, 13.45.

Rachmanto Satuhu,2013. Kendala Dinas Perhubungan Dalam Mengawasi dan Memberi Pembinaan Bagi Pengelola Parkir Untuk Mencegah Penggunaan Klausula Eksonerasi Pada Karcis Parkir (Studi di Dinas Perhubungan Kota Malang), Tugas Akhir, Sarjana Hukum Universitas Brawijaya.

Suryadiputra L. Prototipe.2008. Sistem Parkir otomatis berdasarkan Topologi Kampus Syahdan, Universitas Bina Nusantara, Tugas Akhir, Universitas Bina Nusantara. 
Zairipan Jaya,2010. Penataan Parkir Badan Jalan Pada Jalan Perniagaan Kota Lhokseumawe, Jurnal Portal, ISSN 2085 -
7454, Volume 2 No. 2, Oktober 2010, halaman:99 